\title{
LAS ELECCIONES LEGISLATIVAS DEL 5 DE OCTUBRE DE 1980 EN PORTUGAL
}

La Alianza Democrática, coalición surgida antes de las elecciones de diciembre de 1979 y que agrupa al Partido Popular Democrático del actual primer ministro Sa Carneiro, al Centro Democrático y Social del democristiano Freitas do Amaral y al minúsculo Partido Popular Monárquico, ha salido victoriosa de la confrontación electoral del 5 de octubre pasado al aumentar en trece escaños su mayoría parlamentaria.

La espectación ante estas elecciones era grande, pues no en vano se puede afirmar que sus resultados influirán notablemente en las próximas elecciones presidenciales que en el mes de diciembre de este mismo año celebrará el país vecino.

El programa de Alianza Democrática era un programa de centro-derecha que abogaba en el campo de la política interior por una reforma de la Constitución -que, según los líderes de la alianza, está fuertemente cargada de contenido marxista, colectivista y autogestionario- y el establecimiento de una economía libre de mercado. La fidelidad a la OTAN es, a grandes rasgos, la principal característica de la línea de actuación del futuro gobierno aliancista en política exterior.

La campaña electoral estuvo salpicada de acusaciones entre los diversos partidos en liza, pero sobre todo dirigidas hacia la figura de Francisco Sa Carneiro, líder de Alianza Democrática, acusado por la oposición socialista y comunista de irregularidades financieras

E1 Partido Socialista concurría a las elecciones dentro del Frente Republicano y Socialista, coaligado con dos grupos minoritarios: la Unión de Izquierda Socialista y la Agrupación Socialdemócrata, grupo desgajado del P. P. D. de Sa Carneiro.

EI F.R.S. se presentó ante el electorado con una imagen moderada de tinte socialdemócrata y esbozó un programa de reformas sociales: reforma fiscal, subida de salarios, reforma sanitaria, lucha contra el paro, entre otras.

Completando el espectro político, el Partido Comunista también acudía a las urnas en coalición con el pequeño Movimiento Democrático Portugués -grupo que alinea en sus filas a intelectuales e independientes de izquierda-, formando la Alianza Pueblo Unido.

Ofrezco a continuación un cuadro con los resultados de las elecciones del 5 de octubre en comparación con los de las legislativas inmediatamente anteriores: 
CUADRO I

\section{RESULTADOS ELECTORALES COMPARATIVOS \\ PARA LOS PARTIDOS CON REPRESENTACION PARLAMENTARIA}

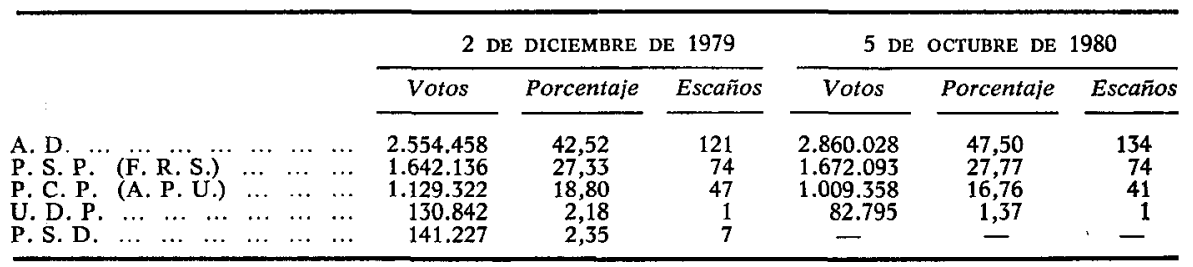

Fuente: Embajada de Portugal.

La A.D. conserva y aumenta su mayoría parlamentaria incrementando su número de seguidores en 305.570 y su representación parlamentaria en 13 escaños. Es la primera vez en la historia de la joven democracia portuguesa que los votos totales de la derecha o el centro-derecha superan a los de los dos grandes partidos de izquierda conjuntamente.

El F.R.S. mantiene sus posiciones con el ligerísimo aumento de 29.957 votos, y los comunistas de la A.P.U. - los más perjudicados por los resultados electorales- ven rebajado su número de electores en la cifra de 119.964, perdiendo además seis escaños en la Asamblea de la República, cinco de ellos en Lisboa y Oporto.

Por circunscripciones electorales, A. D. domina en todas ellas, excepto en la zona de la reforma agraria (Alentejo), en cuyos tres distritos, Beja, Evora y Setúbal, el Partido Comunista Portugués sigue siendo la primera fuerza política.

Seguidamente, y para terminar, ofrezco al lector un cuadro comparativo del comportamiento del cuerpo electoral portugués:

CUADRO II

\section{CUADRO COMPARATIVO DE LA PARTICIPACION CIUDADANA EN LAS DOS ULTIMAS ELECCIONES}

\begin{tabular}{|c|c|c|c|c|}
\hline \multirow[b]{2}{*}{ Participación } & \multicolumn{2}{|c|}{2 DE DICIEMBRE DE 1979} & \multicolumn{2}{|c|}{5 DE OCTUBRE DE 1980} \\
\hline & & Porcentaje & & Porcentaje \\
\hline $\begin{array}{llll}\text { Electores inscritos } & \ldots & \ldots \\
\text { Votos efectivos } & \ldots & \ldots & \ldots \\
\text { Votos nulos } \ldots & \ldots & \ldots & \ldots \\
\text { Votos en blanco } & \ldots & \ldots & \ldots\end{array}$ & $\begin{array}{r}7.249 .346 \\
6.007 .453 \\
120.851 \\
42.863\end{array}$ & $\begin{array}{r}100,00 \\
82,86 \\
2,01 \\
0,71\end{array}$ & $\begin{array}{r}7.087 .559 \\
6.020 .461 \\
108.207 \\
34.760\end{array}$ & $\begin{array}{r}100,00 \\
84,94 \\
1,79 \\
0,57\end{array}$ \\
\hline
\end{tabular}

FuENTE: Embajada de Portugal. 